\title{
Regulated protein aggregation: stress granules and neurodegeneration
}

Benjamin Wolozin

\begin{abstract}
The protein aggregation that occurs in neurodegenerative diseases is classically thought to occur as an undesirable, nonfunctional byproduct of protein misfolding. This model contrasts with the biology of RNA binding proteins, many of which are linked to neurodegenerative diseases. RNA binding proteins use protein aggregation as part of a normal regulated, physiological mechanism controlling protein synthesis. The process of regulated protein aggregation is most evident in formation of stress granules. Stress granules assemble when RNA binding proteins aggregate through their glycine rich domains. Stress granules function to sequester, silence and/or degrade RNA transcripts as part of a mechanism that adapts patterns of local RNA translation to facilitate the stress response. Aggregation of RNA binding proteins is reversible and is tightly regulated through pathways, such as phosphorylation of elongation initiation factor 2a. Microtubule associated protein tau also appears to regulate stress granule formation. Conversely, stress granule formation stimulates pathological changes associated with tau. In this review, I propose that the aggregation of many pathological, intracellular proteins, including TDP-43, FUS or tau, proceeds through the stress granule pathway. Mutations in genes coding for stress granule associated proteins or prolonged physiological stress, lead to enhanced stress granule formation, which accelerates the pathophysiology of protein aggregation in neurodegenerative diseases. Over-active stress granule formation could act to sequester functional RNA binding proteins and/or interfere with mRNA transport and translation, each of which might potentiate neurodegeneration. The reversibility of the stress granule pathway also offers novel opportunities to stimulate endogenous biochemical pathways to disaggregate these pathological stress granules, and perhaps delay the progression of disease.
\end{abstract}

Keywords: Stress granule, TIA-1, TIAR, TTP, G3BP, Prion protein, Microtubule associated protein tau, TDP-43, FUS, FMRP, Prion protein protein synthesis, RNA translation, Alzheimer's disease, Amyotrophic lateral sclerosis, Motor neuron disease, Frontotemporal dementia

\section{Introduction}

The purpose of the review is to provide a new perspective on the role of protein aggregation in neurodegenerative disease. This perspective seeks to incorporate the concept of regulated protein aggregation into the pathophysiology of neurodegenerative diseases. Highlighting the role of regulated protein aggregation in disease pathology provides a biological context for understanding how the process of pathological protein aggregation in disease might evolve, identifies a broad range of proteins that co-aggregate during disease (beyond the classic insoluble protein disease markers),

Correspondence: bwolozin@bu.edu

Departments of Pharmacology and Neurology, Boston University School of Medicine, 72 East Concord St., R614, Boston, MA 02118-2526, USA illuminates signaling cascades regulating many of these aggregation processes and provides potential pathways for therapeutic intervention.

The classic model for pathological protein aggregation in neurodegenerative diseases is based on mass action and energy minimization, as elegantly proposed by Dobson and Lansbury (Figure 1) [1,2]. In this model, aggregation prone proteins are initially present in a cell as monomers. Some of these proteins randomly misfold in a process that is thought to be devoid of biological function. The misfolded proteins oligomerize, and aggregate further to form fibrils. In each case, these processes are thought to occur as undesirable, nonfunctional biological events. The rate of aggregation of these proteins depends on the amount of starting material (monomeric protein) 


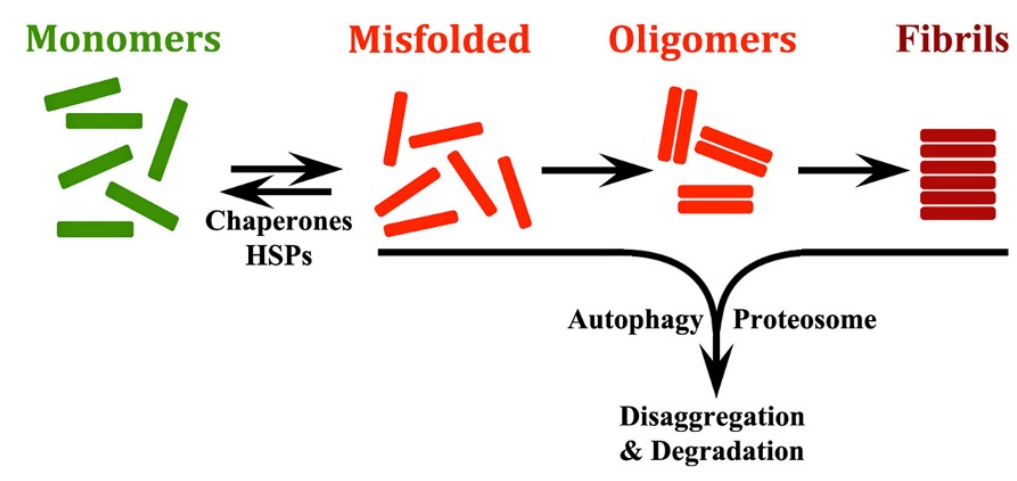

Figure 1 The conventional model for degenerative disease based on mass action and hydrophobic interactions. Monomeric proteins randomly misfold. The chaperone system, including heat shock proteins (HSPs), can reverse the misfolding, and produce normal, functional proteins. However, the misfolded proteins are prone to random oligomerization, and evidence suggests that the resulting oligomers can be toxic. The oligomers aggregate further to form fibrillar aggregates. In each case formation of the misfolded proteins, oligomers and fibrils are considered to lack normal biological functions. These oligomers and fibrillar aggregates can be removed by degradation, which occurs through the actions of the autophagic system and the ubiquitin proteasomal system. Increasing evidence suggests that autophagy is the predominant mechanism of degradation in diseases such as Alzheimer's disease and Parkinson's disease [3].

and the propensity of the protein to aggregate. More starting material leads to more oligomerization by the law of mass action. Greater hydrophobicity also increases the propensity of a protein to oligomerize, due to a greater the need for energy minimization of the hydrophobic interactions. Oligomer and fibril accumulation are minimized by the actions multiple protein chaperones, such as heat shock proteins, as well as by actions of the ubiquitin proteasomal and autophagic systems. Which act to degrade the accumulating oligomers and fibrils $[3,4]$. Despite the elegant complexity of chaperones, the proteasomal system and autophagy, the fundamental concept remains; protein aggregation largely occurs as an unwanted chemical reaction driven by concentration gradients and hydrophobicity. These unwanted oligomers and fibrils appear to cause toxicity, which elicits cell death and inflammation. An example of the broader neurodegeneration hypotheses is the amyloid cascade hypothesis, which links all of this together in a recursive cycle [5].

\section{RNA binding proteins: biology and contributions to neurodegenerative diseases}

The classical process of pathological protein aggregation contrasts with the tightly regulated and reversible process of aggregation that occurs as an intrinsic aspect of the biology of RNA binding proteins. RNA binding proteins have gained attention recently because of the large number of these proteins that are mutated in familial forms of motor neuron diseases. Mutations in RNA binding proteins such as Tar DNA binding protein-43 (TDP-43), Fused in sarcoma (FUS), survival of motor neuron (SMN1), ataxin-2 (ATX2), optineurin (OPT) and angiogenenin (ANG) all cause motor neuron diseases. The roughly 800 proteins in this family exhibit conserved domains structures, and related functions (Figure 2). These RNA binding proteins generally contain two types of conserved domains: glycine rich domains and RNA recognition motifs (RRM). The glycine rich domain is hydrophobic and mediates the reversible aggregation of these proteins; for some RNA binding proteins, such as TIA-1, but not TDP-43, the glycine rich domain shares homology with the yeast prion protein, Sup35 (Figure 2); homology between Sup-35 and TDP-43 is much weaker [6,7]. The RRMs have broad specificity, but differ in the spectrum of transcripts bound. For instance, T-intracellular antigen-1 (TIA-1) recognizes transcripts with a uracyl-rich motif with a 30-37 nucleotide long bipartite motif [8]. TIA1 cytotoxic granule-associated RNA binding protein-like 1 (TIAR) binds transcripts with a 28-32 nucleotide long stem loop element [9]. The $\mathrm{Hu}$ family of RNA binding proteins bind transcripts with a 17-20 nucleotide segment rich in uracyls [10].

The concept of reversible, regulated protein aggregation is central to the hypothesis proposed in this article and demands clarification at the outset. The concept of beneficial misfolding was perhaps first examined in yeast, where the elongation initiation factor Sup35 was shown to misfold in response to environmental (nutritional) stress, and alter the synthesis of proteins in a manner that promotes yeast survival [7]. Sup35 misfolding is stable, is transmitted among yeast, and analogous to the biology of prions [7]. Glycine rich domains in Sup35 mediate the misfolding and also give rise to insoluble protein aggregates, much like amyloidogenic proteins that aggregate in neurodegenerative diseases [13]. The homology between glycine rich domains of some mammalian RNA binding proteins, such as TIA-1, and 


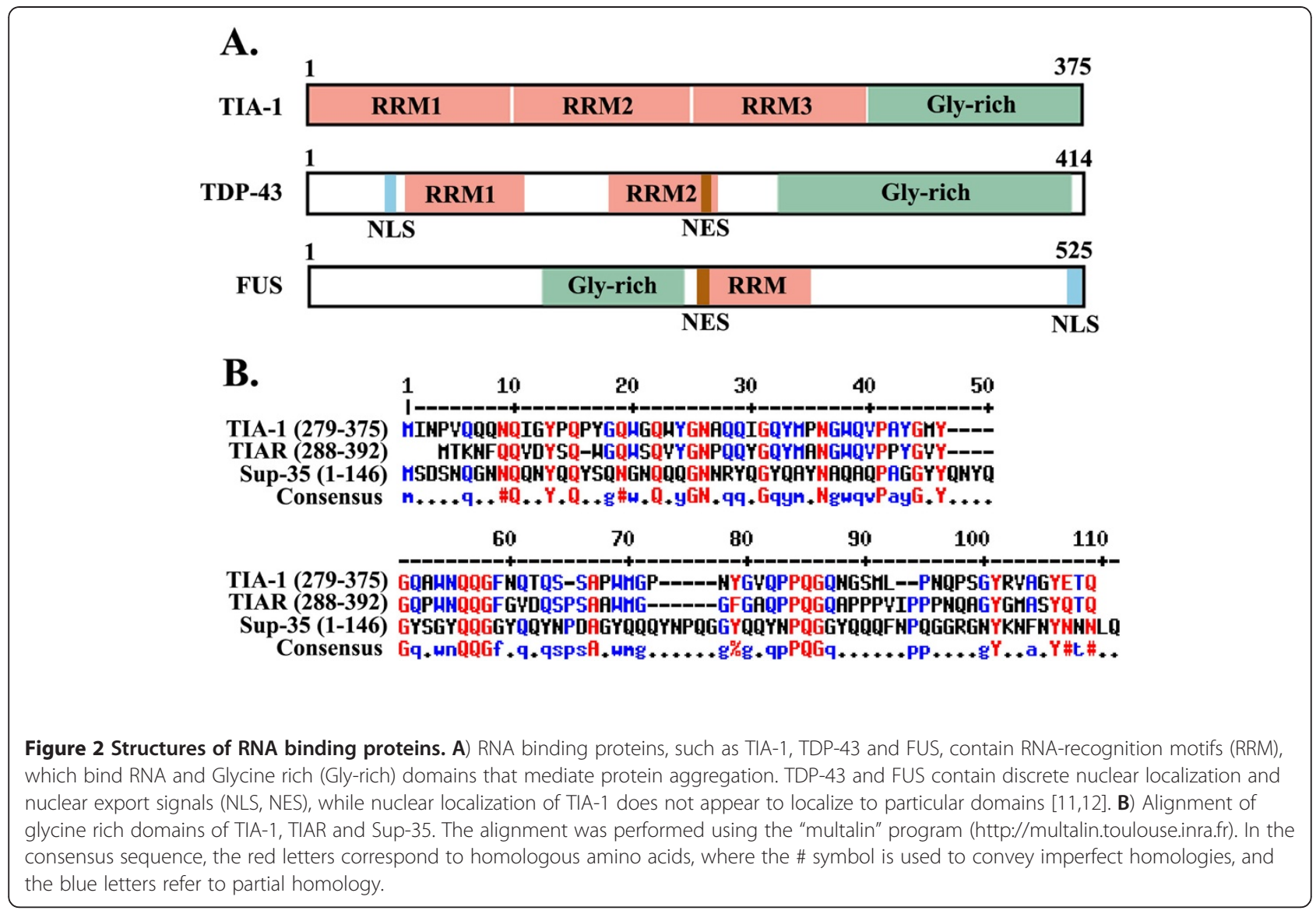

Sup35 highlights a putative role of regulated protein aggregation in the biology of RNA binding proteins (Figure 2). The glycine rich domain of other RNA binding proteins, such as TDP-43, are not homologous to Sup35, but are capable of interacting with Sup35, which emphasizes the biological relatedness of these proteins [14]. The response of many of these RNA binding proteins to stress resembles that of Sup35 in that they aggregate to form insoluble macromolecular structures, composed of RNA binding proteins and mRNA, termed stress granules (see below for further discussion of stress granules) [15]. The resulting aggregates are detergent insoluble, and can be isolated through classic methods used to isolate insoluble proteins aggregates present in brain tissues of subjects with neurodegenerative diseases $[16,17]$.

The aggregation processes characterizing the biology of Sup35 and RNA binding proteins differ from the conventional models of protein aggregation in that they subserve distinct biological functions and are reversible. In order to understand how this biology plays out, it is important to examine the functions of RNA binding proteins throughout the biological cycle of mRNA processing. The functions of RNA binding proteins can generally be divided into nuclear and cytoplasmic activities, each of which is the subject of very large fields of literature. In the nucleus RNA binding proteins regulate mRNA maturation, including splicing, RNA helicase activity, RNA polymerase elongation and nuclear export (Figure 3) [18]. In the cytoplasm RNA binding proteins regulate RNA transport, silencing, translation and degradation (Figure 3) [19]. These RNA binding proteins regulate transcript activity and distribution by forming RNA granules that are macromolecular complexes containing RNA binding proteins and mRNA transcripts consolidated to form granules through protein/protein interactions mediated by the glycine rich domains and protein/mRNA interactions mediated by RRMs [20]. RNA granules vary by molecular composition and function. RNA degradation is mediated by a type of RNA granule, termed the P-body [21]. Transport granules play important roles in neurons, where they move transcripts from the soma into the dendritic, and axonal, arbors [20]. RNA binding protein complexes also mediate the process of activity dependent protein synthesis, which is critical in all aspects of biology, but has attracted particularly strong attention at the synapse where it controls synaptic plasticity, habituation and memory [22]. The synaptic function of one RNA binding protein, Fragile $\mathrm{X}$ mental retardation protein (FMRP) has been studied extensively and is known to regulate 


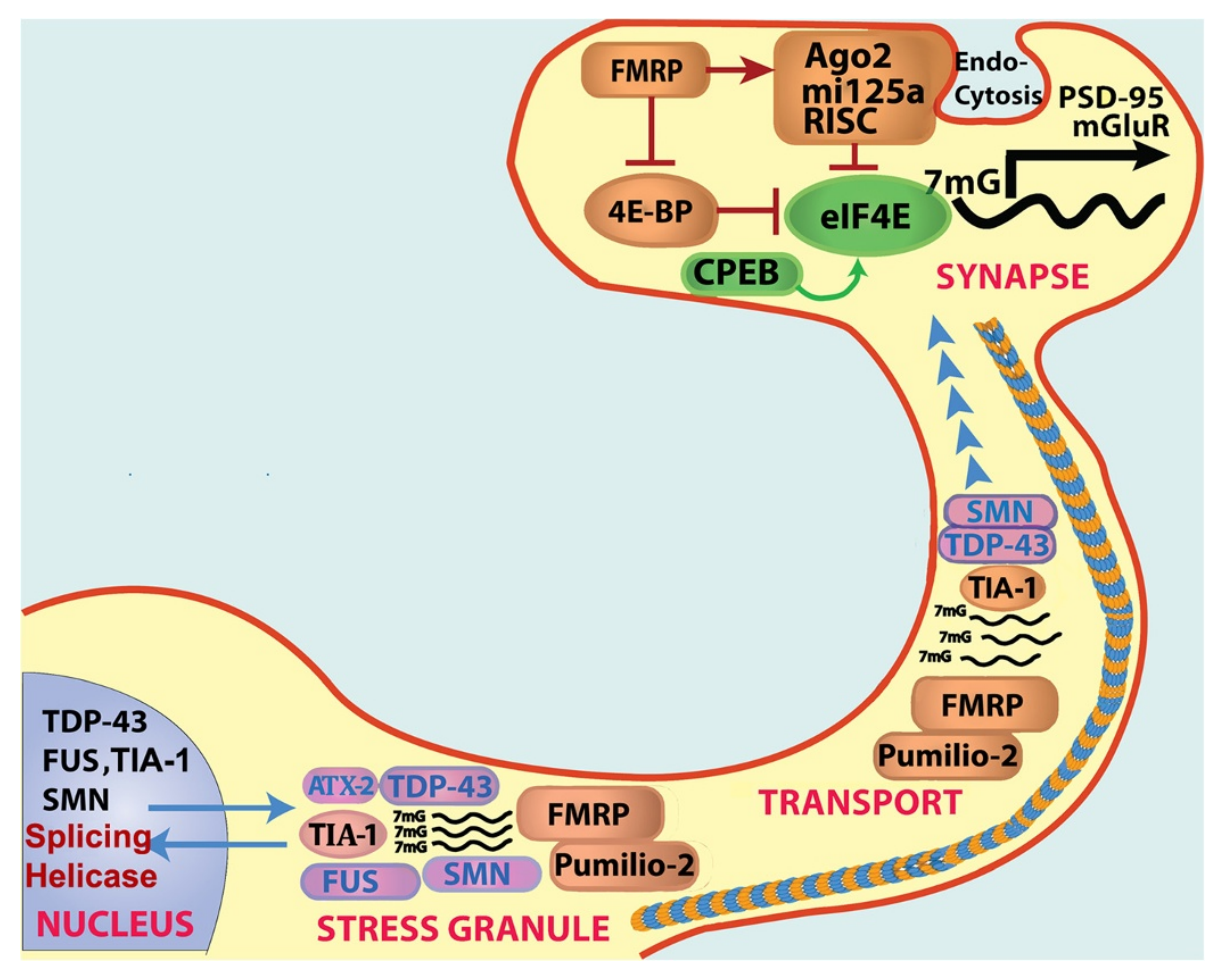

Figure 3 Structure and functions of RNA binding proteins. RNA binding proteins have dual sites of action. In the nucleus, many RNA binding proteins, such as TDP-43, SMN (SMN1 and 2), TIA-1 and FUS regulate mRNA splicing. RNA binding proteins are also present in the cytoplasm and neuronal arbors, where they regulate RNA transport, activity dependent protein synthesis and sequestration of unnecessary transcripts in response to stress. Each of the RNA binding proteins shown in the figure associate with stress granules. TIA-1, SMN and Pumillio-2 are important for trafficking of mRNA in axons and dendrites, which is mediated by microtubules (blue and mustard striped line) and molecular motors. At the synapse, different RNA binding proteins regulate activity dependent translation. Phosphorylation causes 4E-BP to dissociate from elF4E, which initiates translation. FMRP inhibits this process; loss of FMRP expression (such as occurs in fragile $\mathrm{X}$ syndrome) leads to excessive synaptic protein synthesis and excessive dendritic spine density. In contrast, CPEB stimulates activity dependent translation in a process that might involve regulated protein aggregation [27]. Activity dependent protein synthesis is modulated by microRNA. For instance, miR125 regulates the synthesis of mGluR and PSD-95 [24]. miRNA are generated by action of the RISC complex and argonaute, which cleave precursors to generate the miRs. Adapted from Liu-Yesucevitz, et al. [10].

dendritic sprouting [19,23,24]. RNA binding proteins also interface with the micro-RNA system, since both microRNA and RNA binding protein regulate protein synthesis $[25,26]$. The interaction of microRNA with RNA binding protein adds an additional layer of regulatory control.

\section{Stress granules and regulated protein aggregation}

Stress granules (SGs) are another type of RNA granule that is generated in response to stressful conditions. Stressed cells need to produce cytoprotective proteins quickly. This is accomplished by formation of SGs, which shift RNA translation towards cytoprotective proteins [28]. As mentioned above, SGs sequester and silence non-essential transcripts, adapt local patterns of translation within the cell and sequester signaling molecules that regulate cell viability $[19,29]$. SGs also interact with other types of RNA granules. SGs can be seen adjacent to P-bodies, putatively transferring transcripts to the $\mathrm{P}$ bodies for degradation [30]. Neuronal transport granules, which facilitate activity dependent translational machinery at the synapse, can be converted to SGs. Thus, RNA granules interact with each other and can convert their functions depending on conditions.

The process of regulated protein aggregation that characterizes SG formation and allows RNA binding proteins to consolidate transcripts contrasts with vesicle formation, which is the other major cellular mechanism for consolidating molecules. Organelles such as the nucleus, mitochondria, peroxisomes, lysosomes and endosomes consolidate material by surrounding the concentrated target material with one or two lipid membranes. However, regulated protein aggregation achieves molecular consolidation using a process of reversible protein aggregation [31]. In cell culture, SGs form within minutes of a severe stress, and disappear $1-3 \mathrm{hrs}$ after the stress is removed [31]. 
The process of SG formation is best understood for pathways mediated by phosphorylation of eIF $2 \alpha$. Stressful conditions prompt phosphorylation of eIF $2 \alpha$ at serine 51 , which inhibits formation of a complex containing eIF2, GTP and $\mathrm{tRNA}_{\mathrm{i}}^{\text {met }}$ [31]. Stress also induces translocation of many RNA binding proteins from the nucleus to the cytoplasm. During stressful conditions, capped mRNA remains bound to the pre-initiation complex, which contains the other elongation factor binding proteins EF-4A, E and G (Figure 4). This mRNA-protein complex is bound by eIF3, poly-A and nucleating RNA binding proteins, such as TIA-1, TIAR, tristetraprolin (TTP) or GTPase activating protein binding protein (G3BP), which bind the "naked" transcripts in the cytoplasm (Figure 4) [28]. The SGs are initially small, but increase in size as the RNA binding proteins consolidate by binding to each other through the glycine rich protein aggregation domains. This process of secondary maturation of SGs specifically containing G3BP is a prominent cytoplasmic function of TDP-43 [32]. Mutations in RNA binding proteins appear to increase their propensity to aggregate and to form SGs. For instance, disease-linked mutations of TDP-43, FUS and ataxin-2 promote aggregation, either by directly increasing the tendency of the protein to aggregate, or (for many FUS mutations) by preventing nuclear translocation [16,17,33-37]. The SG complex initially forms a structure that is conceptually analogous to a tree, with the glycine rich aggregation domains forming the core of the structure, and the mRNA bound to the RRMI, hanging off the RNA binding proteins. The complex of aggregated RNA binding proteins grows with time as other RNA binding proteins are recruited through binding to the associated transcripts and binding to the protein aggregation domains of other RNA binding proteins (Figure 4). Mature granules contain many RNA binding proteins recruited after the initial

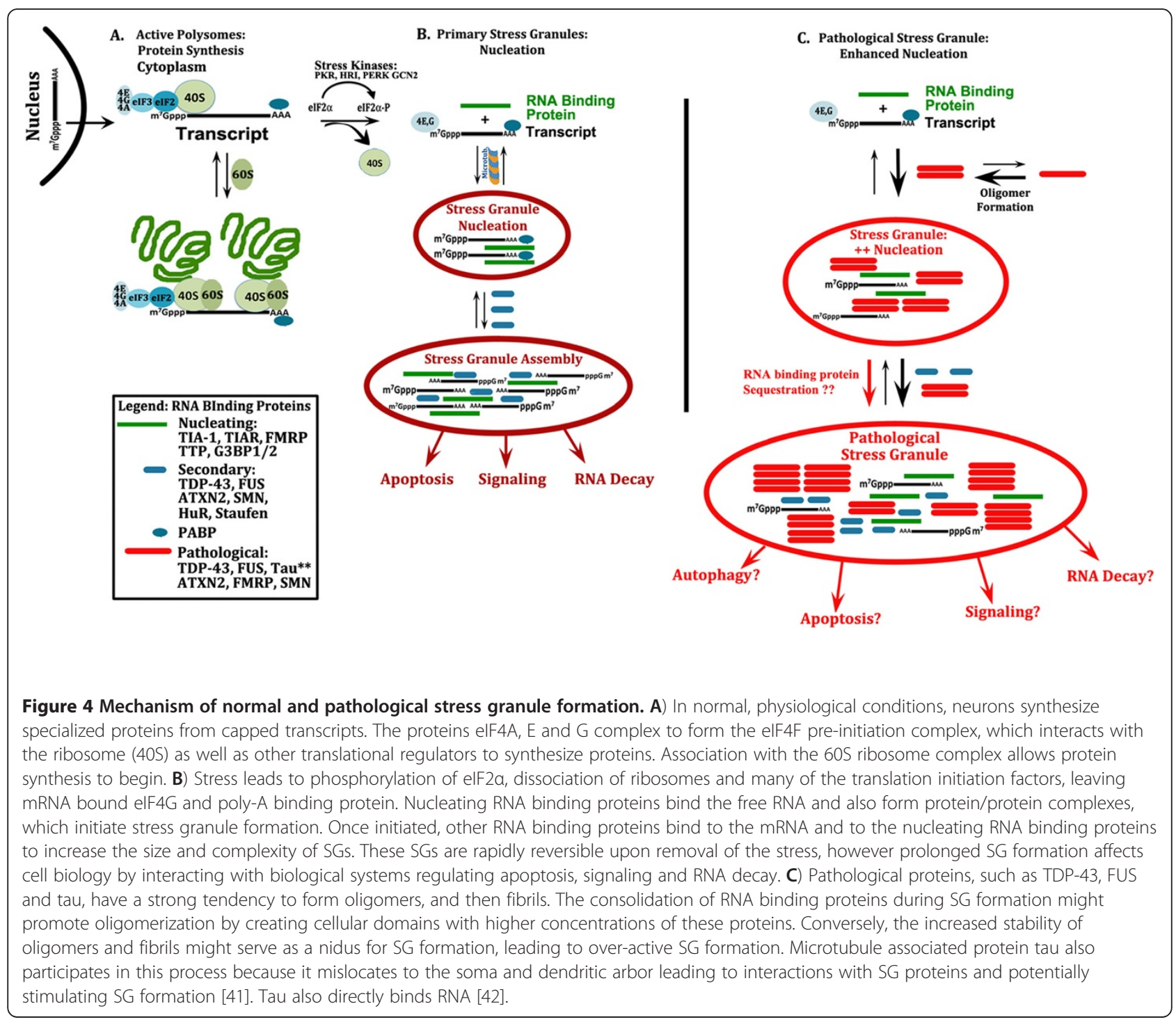


nucleation event. The combined role of protein-protein interactions and protein-RNA interactions presents an important methodological consideration for those investigating SG structure. Biochemical studies of RNA binding protein associations in SGs require pretreatment with RNAse to determine whether SG proteins are directly associated or associated due to mutual binding to mRNA transcripts [16]. Biochemical studies of SGs also demonstrate that the RNA binding proteins present in SGs are triton or SDS insoluble (depending on the protein studied, and the conditions inducing the SG), which is analogous to the biochemistry of proteins aggregates in many neurodegenerative diseases $[6,16,17,28,31,38-40]$.

The importance of SGs for cytoprotection is highlighted by the effects of knockout of SG proteins, such as TIA-1, or inhibition of eIF2 $\alpha$ phosphorylation, which render cells more vulnerable to acute stresses [43,44]. Conversely, inhibiting eIF $2 \alpha$ dephosphorylation protects against some forms of stress [45]. The actual mechanisms by which SGs mediate protection, though, are poorly understood. For instance, conditions of endoplasmic reticulum stress lead to formation of SGs that inhibit cytoplasmic RNA translation, while preferentially retaining RNA translation in the endoplasmic reticulum [46]. Global shifts in RNA translation or RNA degradation are also observed with other stresses, with the exact pattern of RNA translation or degradation varying depending on the particular stress [47]. (The translational response of heat shock protein 70 (HSP70) to stress is nuanced. HSP70 synthesis is stimulated by expression of the pro-aggregation prion domain of TIA-1, but HSP70 synthesis is not stimulated by overexpression of full length TIA-1 [6]. Although the HSP70 transcript contains capped mRNA, HSP70 synthesis does not appear to occur preferentially during SG formation, and might actually be inhibited [48]. On the other hand, protein aggregation, such as those involved in degenerative diseases, stimulates synthesis of HSP70. These seeming contradictions highlight important areas of HSP70 biology that are incompletely understood.) The composition of SGs also varies greatly depending on the type of stress. Since RNA binding proteins all exhibit different RNA binding profiles, the corresponding pattern of RNA translation will vary with the stress. Thus, the changes in RNA translation occurring with stress reflect the biochemical cascades responding to the particular stress, the location of SG formation within the cell, and the pattern of RNA sequestration induced by the composition of the SGs.

Signaling regulates each step of the RNA maturation cycle, including synthesis, splicing, formation of granules (including stress granules), RNA granule transport and activity dependent RNA translation. For instance, phosphorylation of the translation initiation factor, (eIF2 $\alpha$ ) silences translation and is regulated by four different kinases: PERK, HRI, GCN2 and PKR. The regulation of PERK activity has been perhaps the most intensively studied, since PERK mediates stress of the endoplasmic reticulum [49,50]. The SG response is classically designed to cope with a transient stress, and rapidly resolves after the stress is removed [31]. GADD34 is a phosphatase that selectively dephosphorylates eIF $2 \alpha$ [51]. Dephosphorylating eIF2 $\alpha$ disperses SGs and stimulates RNA translation. SG formation is also regulated through eIF $2 \alpha$-independent pathways such as cleavage of tRNA by angiogenin or inhibition of ribosomal scanning $[52,53]$. Signaling cascades such as mTOR, S6 kinase, MAP kinases and Mnks regulate activity dependent translation [54]. The strong role that these signaling cascades play in regulating SG formation demonstrates that RNA translation generally, and SG formation specifically, are both highly regulated processes. Thus, signaling cascades regulate the process of RNA binding protein aggregation, reversibly controlling SG formation or dissolution.

The process of SG formation and dispersion can also be regulated by exogenous application of chemicals that inhibit RNA translation. Cycloheximide and emetine inhibit SG formation by interfering with RNA translation at the step of protein elongation in a manner that maintains the polysomes, which prevents free mRNA from accumulating in the cytoplasm [15]. In contrast, puromycin stimulates SG formation by causing premature chain termination at the ribosome, inducing disassembly of the polysome and producing free mRNA which are then bound by RNA binding proteins [15]. These chemicals are toxic, and thus not useful clinically, but compounds such as salubrinal can induce SG formation without much toxicity [45]. In addition, my laboratory is currently studying novel compounds that inhibit SG formation without toxicity.

The stress response is an integrated response, and this integration also applies to SG production. The RNA binding proteins, TIA-1, TIAR, TTP and G3BP nucleate SGs; a full list of nucleating RNA binding proteins is provided in other reviews, but these four RNA binding proteins are the most commonly examined [29]. Maturation of SGs leads to incorporation of multiple other proteins that regulate other stress response systems. Since SGs are designed to be transient, their formation appears to inhibit irreversible cellular events, such as apoptosis. The pro-apoptotic proteins RACK1, ROCK1 and TRAF2 are all sequestered in SGs, which inhibits the apoptotic response [55,56]. Sequestered RACK1 is unable to activate apoptosis mediated by MTK1, and TRAF2 is unable to activate apoptosis mediated by TNFo and NFKB. Binding of RSK2 and FAST kinase further inhibit apoptosis, and also promotes translational repression [57]. Signaling molecules, such as JNK, 
MKK7 and rhoA are also recruited to SGs, as are scaffold proteins known to regulate other signaling cascades, such as AKAP350A and WDR62, which regulate the responses to cAMP and oxidation, respectively $[58,59]$.

Cytoskeletal machinery facilitates the coalescing of RNA binding proteins to make the SG. Histone deacetylase 6 (HDAC6) is required for this process; it deacetylates tubulin to reduce microtubule-dependent motility, which promotes consolidation of cellular complexes, such as autophagosomes, aggresomes and mitochondria targeted for mitophagy [60-62]. HDAC6 is also required for SG formation [60]. Interestingly, microtubule associated protein tau also regulates transport, classically inhibiting anterograde transport. Stressful conditions lead to tau phosphorylation and mislocalization to the soma and dendrite, where it comes into contact with RNA binding proteins associated with stress granules [63]. Our recent results suggest that tau might modulate SGs [38]. Tau biology is integrated with that of HDAC6, which regulates its turnover [64]. Mutations in dynein motor subunits, such as DLC2A, localize with SGs and are required for $\mathrm{SG}$ formation, just as they are required for other stress processes; these proteins couple SGs to the cytoskeleton and facilitate consolidation into a local region within the cell $[60,65]$. Dynactin subunit I and profilin, both of which regulate actin filaments, cause familial ALS; since the SG protein TDP-43 accumulates in ALS, it is tempting to speculate that these proteins also regulate SG formation [66-68]. Not surprisingly, many of the signaling cascades known to regulate HDAC6 and molecular motors also regulate SG formation, including JNK, MKK7 and rhoA [59,65,69]. This suggests the presence of a common group of proteins contributes to consolidation of many of the structures occurring in response to stress, such as SGs, autophagasomes and aggresomes. The multiple different biological processes that impact on SG formation further emphasizes that the SGs are highly regulated and highly integrated into the biological response to stress and RNA translation.

\section{SGs co-localize with insoluble protein aggregates in neurodegenerative diseases}

The potential importance of SGs for neurodegenerative disease becomes apparent because the process of SG formation presents a biological pathway that could be vulnerable to the protein aggregates that accumulate in neurodegenerative disease. RNA binding proteins are a group of proteins that naturally form insoluble aggregates, yet the aggregated material can disperse and resolubilize [28]. RNA-protein SG complexes are sequestered as SDS-soluble, but triton insoluble protein aggregates [16]. Most, if not all, of the RNA binding protein linked to neurodegenerative diseases associate with SGs in cell culture. TDP-43, FUS, ataxin-2, SMN, optineurin and angiogenin have all been shown to co-localize with classic SG markers (TIA-1, TIAR and/or G3BP) in cells undergoing stress [16,33,34,37,70]. SG proteins such as TIA-1, eIF3 and poly-A binding protein, PABP also co-localize with neuropathology in brain tissue of subjects with AD, FTDP-17, FTLD-TDP and ALS, or animal models of these diseases [16,38]. In addition, SMN, huntingtin and $\mathrm{PrP}^{\mathrm{SC}}$ associate with SGs and modulate SG formation in cultured cells $[39,40,71]$. Our studies of brain tissues from animal models of tauopathy indicate that the solubility of different SG proteins varies dramatically among particular SG proteins. Biochemical fractionation of proteins from these samples shows that RNA binding proteins such as TIA-1, TTP and G3BP form aggregates that are triton insoluble but sarkosyl soluble [38]. In contrast, pathological aggregates of tau or $\beta$-amyloid are highly insoluble [38]. Interestingly, TDP-43 and FUS also form highly insoluble inclusions [16,34]. Thus the proteins that form the most insoluble aggregates are those that have been shown to cause familial forms of neurodegenerative disease, including TDP-43, FUS and tau. Our studies (discussed below) also point to a close link between tau and SG biology. Parkinson's disease is perhaps the outlier, because $\alpha$-synuclein and Lewy bodies have not yet been associated with SG biology, but leucine rich repeat kinase 2 (LRRK2) is known to modulate RNA translation, which points to a link with SG biology [72]. These results suggest that disease-linked proteins form pathological aggregates that are often, if not always, co-localized with SG proteins.

The examples of AD and FTLD-17 are particularly striking because in both of these tauopathies, the load of SG positive inclusions that form is large, exhibiting a density that is equal to or greater than the load of neurofibrillary tangles [38]. SG proteins such as TIA-1 and TTP identify most neurofibrillary tangles, but also identify inclusions that appear to lack reactivity with antibodies to phospho-tau (e.g., PHF-1 or CP13) or conformationally altered tau (e.g., Alz-50 or MC1). A different SG protein, G3BP, identifies neurons that are predominantly negative for pathological tau protein [38]. The abundance of SGs in tauopathies suggests that the load of pathological inclusions is much greater than would be apparent by simply using markers of tau protein.

The co-localization of SGs with neuropathology in the human brain suggests shared mechanisms. I propose that the aggregation of pathological proteins (e.g., tau or TDP-43) stimulates SG formation, and formation of SGs accelerates aggregation of the pathological proteins (Figure 4). As mentioned above, disease-linked pathological proteins, such as tau and TDP-43, are known to exhibit a tendency to form stable, insoluble protein aggregates. The interaction between pathology of SGs is easy to envision for RNA binding proteins that exhibit disease-linked mutations, such as TDP-43, FUS, 
optineurin and angiogenin, each of which are linked to ALS. Disease linked mutations in these proteins increase the tendency of the protein to aggregate. In addition, the aggregates that form appear to be highly insoluble, highly stable complexes. Since these proteins normally exist in equilibrium between dispersed, soluble proteins and aggregated, insoluble complexes; aggregation-accelerating mutations would shift the equilibrium, leading to increased SG formation and formation of the stable, long-lived protein aggregates that we associate with disease pathology (Figure 4). The presence of more aggregates and/or aggregates with enhanced stability might also increase formation of mature SGs around the aggregates, much like the normal evolution of SGs. This process of SG growth is analogous to cross-seeding, and normally forms the basis of SG maturation. Pathological cross-seeding already has been shown in cell culture for polyglutamine rich proteins, such as huntingtin, and for stimulation of tau aggregation by $\alpha$-synuclein [71,73]. This same process of accelerated cross-seeding might occur in the brain for other pathological proteins, more generally. The formation of longlived, stable insoluble protein aggregates could shift the equilibrium of regulated protein aggregation towards aggregation, leading to accelerated, long-lived SG formation (Figure 4). These highly insoluble aggregates could also serve as a nidus for further aggregation of SGs, by binding with other RNA binding proteins and also binding RNA as part of the process of SG maturation. The result would be an overactive SG pathway.

Overactive SG formation in tauopathies might seem puzzling, since tau was not previously considered to be a SG protein. However, our studies using transfected $\mathrm{SH}$ SY5Y cells demonstrate that SG formation stimulates formation of phosphorylated tau inclusions [38]. Even more strikingly, tau appears to stimulate SG formation [38]. The latter result suggests that tau actually contributes to the SG response, and might explain the strong link between tauopathy and SGs. Evaluation of tau biology suggests a mechanism for interaction with SGs. Tau expression is normally restricted to the axon, while the RNA translation machinery is more abundant in the soma and dendrites. However, stress stimulates tau phosphorylation and mislocalization to the soma and dendrite where it can interact with RNA binding proteins, as well as RNA, associated with SGs $[41,63]$. This interaction accelerates SG formation, and also might accelerate tau aggregation. The mechanism remains to be determined, but the building blocks underlying a putative mechanism are evident. Tau binds SG proteins, such as TIA-1 and TTP, which provides for a direct interaction between tau and SGs [38]. In addition, RNA is a known stimulus for tau aggregation in vitro [74], which makes it possible that the RNA associated with SGs might further promote tau aggregation. Thus, in the case of tauopathies, aggregation of tau protein stimulates SG formation, leading to enhanced SG formation, and SG formation might stimulate tau aggregation.

Whether the overactive SG formation is good or bad remains to be determined. The response of neurons to SG formation might be analogous to the responses to autophagy; some autophagy is needed for survival, but too much autophagy can be deleterious. Neurons require SGs for an effective stress response, but overactive, overly stable SG complexes could easily interfere with neuronal function by silencing transcripts and sequestering important proteins. Mutations associated with disease-linked proteins increase the aggregation propensity, which provides a direct mechanism for overactive SG formation. Chronic stressful diseases or environmental conditions might also stimulate overactive SG formation. For instance, the oxidative stress associated with aging, the trophic stress associated with diabetes or the physical stress associated with chronic traumatic encephalopathy all enhance SG formation creating the conditions for pathological aggregation [75-77].

The effects of modulating the protein synthesis/SG pathway were recently evaluated in an animal model of Creutzfeld Jacob disease, where pathological misfolding of PrP precipitates neurodegeneration. Mallucci and colleagues forced expression of GADD34 to reduce eIF2 $\alpha$ phosphorylation, inhibit SG formation and stimulate protein synthesis [51]. This intervention reduced PrPinduced neurodegeneration. In contrast, salubrinal, which increases eIF $2 \alpha$ phosphorylation, increased SG formation, inhibited protein synthesis, and accelerated neurodegeneration [51]. These results suggest that inhibiting the SG pathway and stimulating protein synthesis can inhibit PrP-mediated neurodegeneration. The discovery of overactive SG formation in other diseases raises the possibility that these pathways are over-active in multiple neurodegenerative diseases, and that pharmacotherapy targeting SG formation might be neuroprotective.

\section{Critical questions}

SG biology provides a highly useful paradigm for understanding neurodegenerative diseases, but important questions related to SG biology remain to be investigated. The major questions can be divided into four areas:

1. What are the consequences of stress granule persistence? SGs are classically transient structures but in neurodegenerative diseases they become associated with pathological structures and appear to persist. The biological consequences of this persistence are not known. Persistent SGs might protect the neuron by acting as a sink for sequestering toxic oligomers. However, persistent 
SGs might also serve as a sink for sequestering RNA binding proteins, which would interfere with their normal function. In ALS, for instance, the pathology is notable for the loss of nuclear TDP-43 and FUS. It seems possible that these proteins might be absorbed and sequestered by stable SGs. For instance, a recent study compared the effects of TDP-43 and FUS knockdown, and identified a discrete number of very long, brain specific transcripts that are regulated in common, including parkin and neurexin 3 [78]. Misregulation of these genes might contribute to disease. Kinetics is another critical consideration. A small group of nucleating RNA binding proteins initiate SG formation, which then continue to grow and incorporate other RNA binding proteins. Persistence of SGs might allow other proteins to interact with SGs, but with delayed kinetics. This could lead to ubiquitination of SGs, interactions of SGs with the autophagic system or dysfunction of pro-apoptotic proteins [57].

2. Does translational repression contribute to the pathophysiology of neurodegenerative diseases? The role of the SG pathway in translational repression also raises inherent questions about the role of translation repression in the pathophysiology of disease; the ability of GADD34 to delay progression of PrP mediated degeneration emphasizes the potential significance for therapy of neurodegenerative diseases [51]. It seems likely that as we understand how to manipulate this highly regulated pathway, we will better understand the biology of neurons and possibly gain insight into pathways for intervention in neurodegenerative diseases by modulating protein translation.

3. Do deficits in axonal and dendritic transport affect stress granule biology? Multiple genes linked to transport are genetically implicated in neurodegenerative diseases. Since RNA transport represents a large part of extra-nuclear function of RNA binding proteins, it seems possible that the pathophysiology of the transport biology might be linked to the pathophysiology of RNA binding proteins. Tau protein, which is a major component of the pathology in AD and FTD, regulates microtubule stability [41]. Mutations in transport proteins profillin, kinensin, dynein and dynactin are all associated with motor neuron diseases [66,79-81]. Whether these mutations affect transport of mRNA to the synapse or SG formation remains an open question.

4. $\alpha$-Synuclein and Parkinson's disease: Most of the genes linked to Parkinson's disease appear to be most important to the biology of organelles and vesicles: mitochondria, autophagy, mitophagy, lysosomal function and vesicular endocytosis [82]. The link between Parkinson's disease, RNA binding proteins and regulated protein aggregation remains nebulous. Some recent studies point to links with RNA translation and regulated protein aggregation, but the studies are small in number. Mutations in TDP-43 have been identified in some cases of PD [83]. TDP43 pathology is present in diffuse Lewy body disease, which provides some support suggesting the involvement of RNA binding proteins in synucleinopathies, but no such pathology has been reported for PD [84-86]. Some studies also implicate RNA translation in the pathophysiology of PD.

Abeliovich's group identified an association between the length of the 3' UTR of $\alpha$-synuclein and Parkinson's disease [87]. Finally, LRRK2 is implicated in the regulation of RNA translation [72]. Each of these connections are interesting, but whether these impact on the process of regulated protein aggregation remains to be determined.

5. What are the pathways that regulate aggregation and dis-aggregation? While some of the pathways regulating SG formation are defined, it seems likely that other pathways will be identified. In addition, very little is known about the mechanisms that disaggregate SGs. The ability of SGs to rapidly disperse raises the specter of biochemical pathways that can disperse (at least some) protein aggregates quicker and more effectively than the classic pathways known for HSPs, the ubiquitin proteasomal system and autophagy. Identifying such pathways could be particularly important in the context of neurodegenerative diseases where SG formation might be over active.

\section{Conclusion}

This review presents the concept of regulated protein aggregation. The idea that protein aggregation might be physiological and regulated presents a novel paradigm for the field of neurodegenerative research. The classic model of pathological protein aggregation is a process that occurs through random interaction of misfolded proteins. In this review, I point out that many of the proteins linked to neurodegenerative disease assume a conformation that favors aggregation as part of the normal biology of RNA granule formation generally, and SG formation specifically. This physiological aggregation becomes pathological when the pro-aggregation state is favored because of mutations, other disease processes or environmental conditions. Linkage of pathological protein aggregation to the normal biological process of regulated protein aggregation is important because RNA granule and SG formation are regulated by signaling cascades and are reversible. The role of biochemical 
pathways in regulating regulated protein aggregation presents potentially novel targets for pharmacotherapy of neurodegenerative disease.

\section{Abbreviations}

AD: Alzheimer's disease; Ago2: Argonaute-2, eukaryotic translation initiation factor 2C; ALS: Amyotrophic lateral sclerosis; ANG: Angiogenenin; ATX2: Ataxin-2; CPEB: Cytoplasmic polyadenylation element binding protein; 4E-BP: Eukaryotic translation initiation factor 4E-binding protein; elF2, 3: Elongation initiation factor 2, 3; elF4E: Elongation initiation factor 4E; FMRP: Fragile X mental retardation protein; FTDP-17: Frontotemporal dementia with parkinsonism, chromosome 17; FTLD-TDP: Frontotemporal lobar dementia with TDP-43; FUS: Fused in sarcoma; G3BP: GTPase activating protein binding protein; GCN2: GCN2 elF2a kinase; elF2a kinase 4; HDAC6: Histone deacetylase 6; HRI: Heme regulated initiation factor $2 a$ kinase; elF2a kinase 1; HSP70: Heat shock protein 70; HuR: Hu antigen R, ELAV-like protein 1; LRRK2: Leucine rich repeat kinase 2; 7mG: 7 methylguanosine; mGluR: Metabotropic glutamate receptor mi125a: MicroRNA 125a; OPT: Optineurin; PABP: Poly-A binding protein; PERK: PRKR-like endoplasmic reticulum kinase; elF2a kinase 3; PKR: P1/elF-2A protein kinase; elF2a kinase 2; PrPsc: Prion protein, pathological form; PSD95: Post-synaptic density protein 95; RISC: RNA induced silencing complex; RRM: RNA recognition motifs; SG: Stress granule; SMN: Survival of motor neuron; TDP-43: Tar DNA binding protein-43; TIA-1: T-intracellular antigen-1; TIAR: TIA1 cytotoxic granule-associated RNA binding protein-like 1; TTP: Tristetraprolin

\section{Competing interests}

BW has applied for a patent related to the application of stress granule biology to neurodegenerative disease.

\section{Authors' contributions}

BW prepared and wrote the manuscript.

\section{Acknowledgements}

This research was supported by grant awards to BW from NIEHS, NINDS and American Health Assistance Foundation.

Received: 2 October 2012 Accepted: 13 November 2012

Published: 20 November 2012

\section{References}

1. Dobson CM: Protein folding and misfolding. Nature 2003, 426:884-890

2. Jarrett J, Jarrett J, Lansbury P: Seeding "one-dimensional crystallization" of amyloid: a pathogenic mechanism in Alzheimer's disease and scrapie? Cell 1993, 73(P Lansbury):1055-1058

3. Bandhyopadhyay U, Cuervo AM: Chaperone-mediated autophagy in aging and neurodegeneration: lessons from alpha-synuclein. Exp Gerontol 2006, 42:120-128

4. Powers ET, Morimoto RI, Dillin A, Kelly JW, Balch WE: Biological and chemical approaches to diseases of proteostasis deficiency. Annu Rev Biochem 2009, 78:959-991.

5. Selkoe DJ, Schenk D: Alzheimer's disease: molecular understanding predicts amyloid-based therapeutics. Annu Rev Pharmacol Toxicol 2003, 43:545-584

6. Gilks N, Kedersha N, Ayodele M, Shen L, Stoecklin G, Dember LM, Anderson P. Stress granule assembly is mediated by prion-like aggregation of TIA-1. Mol Biol Cell 2004, 15:5383-5398

7. Serio TR, Lindquist SL: [PSI+], SUP35, and chaperones. Adv Protein Chem 2001, 57:335-366

8. Lopez de Silanes I, Galban S, Martindale JL, Yang X, Mazan-Mamczarz K, Indig FE, Falco G, Zhan M, Gorospe M: Identification and functional outcome of mRNAs associated with RNA-binding protein TIA-1. Mol Cell Biol 2005, 25:9520-9531.

9. Kim HS, Kuwano Y, Zhan M, Pullmann R Jr, Mazan-Mamczarz K, Li H, Kedersha N, Anderson P, Wilce MC, Gorospe M, Wilce JA: Elucidation of a C-rich signature motif in target mRNAs of RNA-binding protein TIAR. Mol Cell Biol 2007, 27:6806-6817.

10. Lopez de Silanes I, Zhan M, Lal A, Yang X, Gorospe M: Identification of a target RNA motif for RNA-binding protein HuR. Proc Natl Acad Sci U S A 2004, 101:2987-2992.
11. Zhang T, Delestienne N, Huez G, Kruys V, Gueydan C: Identification of the sequence determinants mediating the nucleo-cytoplasmic shuttling of TIAR and TIA-1 RNA-binding proteins. J Cell Sci 2005, 118:5453-5463.

12. Dormann D, Haass C: TDP-43 and FUS: a nuclear affair. Trends NeurosCi 2011, 34:339-348.

13. Goehler H, Droge A, Lurz R, Schnoegl S, Chernoff YO, Wanker EE: Pathogenic polyglutamine tracts are potent inducers of spontaneous Sup35 and Rnq1 amyloidogenesis. PLoS One 2010, 5:e9642.

14. Wang IF, Chang HY, Hou SC, Liou GG, Way TD, James Shen CK: The selfinteraction of native TDP- $43 \mathrm{C}$ terminus inhibits its degradation and contributes to early proteinopathies. Nat Commun 2012, 3:766.

15. Kedersha N, Anderson P: Mammalian stress granules and processing bodies. Methods Enzymol 2007, 431:61-81

16. Liu-Yesucevitz L, Bilgutay A, Zhang YJ, Vanderweyde T, Citro A, Mehta T, Zaarur N, McKee A, Bowser R, Sherman M, Petrucelli L, Wolozin B: Tar DNA binding protein-43 (TDP-43) associates with stress granules: analysis of cultured cells and pathological brain tissue. PLoS One 2010, 5:e13250

17. Johnson BS, Snead D, Lee JJ, McCaffery JM, Shorter J, Gitler AD: TDP-43 is intrinsically aggregation-prone, and amyotrophic lateral sclerosis-linked mutations accelerate aggregation and increase toxicity. J Biol Chem 2009, 284:20329-20339.

18. Heyd F, Lynch KW: Degrade, move, regroup: signaling control of splicing proteins. Trends Biochem Sci 2011, 36:397-404

19. Liu-Yesucevitz L, Bassell GJ, Gitler AD, Hart AC, Klann E, Richter JD, Warren ST, Wolozin B: Local RNA translation at the synapse and in disease. J Neurosci 2011, 31:16086-16093.

20. Krichevsky AM, Kosik KS: Neuronal RNA granules: a link between RNA localization and stimulation-dependent translation. Neuron 2001, 32:683-696.

21. Thomas MG, Loschi M, Desbats MA, Boccaccio GL: RNA granules: the good, the bad and the ugly. Cell Signal 2011, 23:324-334

22. Hoeffer CA, Klann E: mTOR signaling: at the crossroads of plasticity, memory and disease. Trends Neurosci 2010, 33:67-75.

23. Bassell GJ, Warren ST: Fragile $X$ syndrome: loss of local mRNA regulation alters synaptic development and function. Neuron 2008, 60:201-214.

24. Muddashetty RS, Nalavadi VC, Gross C, Yao X, Xing L, Laur O, Warren ST, Bassell GJ: Reversible inhibition of PSD-95 mRNA translation by miR125a, FMRP phosphorylation, and mGluR signaling. Mol Cell 2011 42:673-688.

25. Gibbings DJ, Ciaudo C, Erhardt M, Voinnet O: Multivesicular bodies associate with components of miRNA effector complexes and modulate miRNA activity. Nat Cell Biol 2009, 11:1143-1149.

26. Schratt G: microRNAs at the synapse. Nat Rev Neurosci 2009, 10:842-849.

27. Si K, Choi YB, White-Grindley E, Majumdar A, Kandel ER: Aplysia CPEB can form prion-like multimers in sensory neurons that contribute to longterm facilitation. Cell 2010, 140:421-435.

28. Kedersha N, Cho MR, Li W, Yacono PW, Chen S, Gilks N, Golan DE, Anderson P. Dynamic shuttling of TIA-1 accompanies the recruitment of mRNA to mammalian stress granules. J Cell Biol 2000, 151:1257-1268.

29. Anderson P, Kedersha N: Stress granules: the Tao of RNA triage. Trends Biochem Sci 2008, 33:141-150

30. Parker R, Sheth U: P bodies and the control of mRNA translation and degradation. Mol Cell 2007, 25:635-646.

31. Kedersha NL, Gupta M, Li W, Miller I, Anderson P: RNA-binding proteins TIA-1 and TIAR link the phosphorylation of elF-2 alpha to the assembly of mammalian stress granules. J Cell Biol 1999, 147:1431-1442.

32. McDonald KK, Aulas A, Destroismaisons L, Pickles S, Beleac E, Camu W, Rouleau GA, Vande Velde C: TAR DNA-binding protein 43 (TDP-43) regulates stress granule dynamics via differential regulation of $\mathrm{G} 3 \mathrm{BP}$ and TIA-1. Hum Mol Genet 2011, 20:1400-1410

33. Colombrita C, Zennaro E, Fallini C, Weber M, Sommacal A, Buratti E, Silani V, Ratti A: Tdp-43 is recruited to stress granules in conditions of oxidative insult. J Neurochem 2009, 111:1051-1061.

34. Bosco DA, Lemay N, Ko HK, Zhou H, Burke C, Kwiatkowski TJ Jr, Sapp P, McKenna-Yasek D, Brown RH Jr, Hayward LJ: Mutant FUS proteins that cause amyotrophic lateral sclerosis incorporate into stress granules. Hum Mol Genet 2011, 19:4160-4175.

35. Dormann D, Rodde R, Edbauer D, Bentmann E, Fischer I, Hruscha A, Than ME, Mackenzie IR, Capell A, Schmid B, Neumann M, Haass C: ALS-associated fused in sarcoma (FUS) mutations disrupt transportin-mediated nuclear import. EMBO J 2011, 29:2841-2857. 
36. Elden AC, Kim HJ, Hart MP, Chen-Plotkin AS, Johnson BS, Fang X, Armakola M, Geser F, Greene R, Lu MM, Padmanabhan A, Clay-Falcone D, McCluskey L, Elman L, Juhr D, Gruber PJ, Rub U, Auburger G, Trojanowski JQ, Lee VM, Van Deerlin VM, Bonini NM, Gitler AD: Ataxin-2 intermediate-length polyglutamine expansions are associated with increased risk for ALS. Nature 2010, 466:1069-1075.

37. Hart MP, Gitler AD: ALS-associated ataxin 2 PolyQ expansions enhance stress-induced caspase 3 activation and increase TDP-43 pathological modifications. J Neurosci 2012, 32:9133-9142.

38. Vanderweyde T, Yu H, Varnum M, Liu-Yesucevitz L, Citro A, Ikezu T, Duff K, Wolozin B: Contrasting pathology of stress granule proteins TIA-1 and G3BP in tauopathies. J Neurosci 2012, 32:8270-8283.

39. Waelter S, Boeddrich A, Lurz R, Scherzinger E, Lueder G, Lehrach H, Wanker EE Accumulation of mutant huntingtin fragments in aggresome-like inclusion bodies as a result of insufficient protein degradation. Mol Biol Cell 2001, 12:1393-1407.

40. Goggin K, Beaudoin S, Grenier C, Brown AA, Roucou X: Prion protein aggresomes are $\operatorname{poly}(A)+$ ribonucleoprotein complexes that induce a PKR-mediated deficient cell stress response. Biochim Biophys Acta 2008, 1783:479-491.

41. Stamer $K$, Vogel $R$, Thies E, Mandelkow E, Mandelkow EM: Tau blocks traffic of organelles, neurofilaments, and APP vesicles in neurons and enhances oxidative stress. J Cell Biol 2002, 156:1051-1063.

42. Friedhoff $P$, Schneider A, Mandelkow EM, Mandelkow E: Rapid assembly of Alzheimer-like paired helical filaments from microtubule-associated protein tau monitored by fluorescence in solution. Biochemistry 1998, 37:10223-10230.

43. Phillips K, Kedersha N, Shen L, Blackshear PJ, Anderson P: Arthritis suppressor genes TIA-1 and TTP dampen the expression of tumor necrosis factor alpha, cyclooxygenase 2, and inflammatory arthritis. Proc Natl Acad Sci U S A 2004, 101:2011-2016.

44. Jiang HY, Wek SA, McGrath BC, Scheuner D, Kaufman RJ, Cavener DR, Wek RC: Phosphorylation of the alpha subunit of eukaryotic initiation factor 2 is required for activation of NF-kappaB in response to diverse cellular stresses. Mol Cell Biol 2003, 23:5651-5663.

45. Boyce M, Bryant KF, Jousse C, Long K, Harding HP, Scheuner D, Kaufman RJ, Ma D, Coen DM, Ron D, Yuan J: A selective inhibitor of elF2alpha dephosphorylation protects cells from ER stress. Science 2005, 307:935-939.

46. Unsworth $H$, Raguz S, Edwards HJ, Higgins CF, Yague E: mRNA escape from stress granule sequestration is dictated by localization to the endoplasmic reticulum. FASEB J 2010, 24:3370-3380.

47. Munchel SE, Shultzaberger RK, Takizawa N, Weis K: Dynamic profiling of mRNA turnover reveals gene-specific and system-wide regulation of mRNA decay. Mol Biol Cell 2012, 22:2787-2795.

48. Hu S, Claud EC, Musch MW, Chang EB: Stress granule formation mediates the inhibition of colonic Hsp70 translation by interferon-gamma and tumor necrosis factor-alpha. Am J Physiol Gastrointest Liver Physiol 2012, 298:G481-G492.

49. Colla E, Coune P, Liu Y, Pletnikova O, Troncoso JC, Iwatsubo T, Schneider BL, Lee MK: Endoplasmic reticulum stress is important for the manifestations of alpha-synucleinopathy in vivo. J Neurosci 2012, 32:3306-3320.

50. Saxena S, Cabuy E, Caroni P: A role for motoneuron subtype-selective ER stress in disease manifestations of FALS mice. Nat Neurosci 2009, 12:627-636.

51. Moreno JA, Radford H, Peretti D, Steinert JR, Verity N, Martin MG, Halliday M, Morgan J, Dinsdale D, Ortori CA, Barrett DA, Tsaytler P, Bertolotti A, Willis AE, Bushell M, Mallucci GR: Sustained translational repression by elF2alpha-P mediates prion neurodegeneration. Nature 2012, 485:507-511.

52. Emara MM, Ivanov P, Hickman T, Dawra N, Tisdale S, Kedersha N, Hu GF, Anderson P: Angiogenin-induced tRNA-derived stress-induced RNAs promote stress-induced stress granule assembly. J Biol Chem 2010, 285:10959-10968.

53. Dang Y, Kedersha N, Low WK, Romo D, Gorospe M, Kaufman R, Anderson P, Liu JO: Eukaryotic initiation factor 2alpha-independent pathway of stress granule induction by the natural product pateamine a. J Biol Chem 2006, 281:32870-32878.

54. Banko JL, Hou L, Poulin F, Sonenberg N, Klann E: Regulation of eukaryotic initiation factor $4 \mathrm{E}$ by converging signaling pathways during metabotropic glutamate receptor-dependent long-term depression. J Neurosci 2006, 26:2167-2173.
55. Arimoto K, Fukuda H, Imajoh-Ohmi S, Saito H, Takekawa M: Formation of stress granules inhibits apoptosis by suppressing stress-responsive MAPK pathways. Nat Cell Biol 2008, 10:1324-1332.

56. Kim WJ, Back SH, Kim V, Ryu I, Jang SK: Sequestration of TRAF2 into stress granules interrupts tumor necrosis factor signaling under stress conditions. Mol Cell Biol 2005, 25:2450-2462.

57. Eisinger-Mathason TS, Andrade J, Groehler AL, Clark DE, Muratore-Schroeder TL, Pasic L, Smith JA, Shabanowitz J, Hunt DF, Macara IG, Lannigan DA: Codependent functions of RSK2 and the apoptosis-promoting factor TIA-1 in stress granule assembly and cell survival. Mol Cell 2008, 31:722-736.

58. Kolobova E, Efimov A, Kaverina I, Rishi AK, Schrader JW, Ham AJ, Larocca MC, Goldenring JR: Microtubule-dependent association of AKAP350A and CCAR1 with RNA stress granules. Exp Cell Res 2009, 315:542-555.

59. Wasserman T, Katsenelson K, Daniliuc S, Hasin T, Choder M, Aronheim A: A novel c-Jun N-terminal kinase (JNK)-binding protein WDR62 is recruited to stress granules and mediates a nonclassical JNK activation. Mol Biol Cell 2010, 21:117-130.

60. Kwon S, Zhang Y, Matthias P: The deacetylase HDAC6 is a novel critical component of stress granules involved in the stress response. Genes Dev 2007, 21:3381-3394.

61. Lee JY, Koga H, Kawaguchi Y, Tang W, Wong E, Gao YS, Pandey UB, Kaushik S, Tresse E, Lu J, Taylor JP, Cuervo AM, Yao TP: HDAC6 controls autophagosome maturation essential for ubiquitin-selective quality-control autophagy. EMBO J 2010, 29:969-980.

62. Lee JY, Nagano Y, Taylor JP, Lim KL, Yao TP: Disease-causing mutations in parkin impair mitochondrial ubiquitination, aggregation, and HDAC6dependent mitophagy. J Cell Biol 2010, 189:671-679.

63. Hoover BR, Reed MN, Su J, Penrod RD, Kotilinek LA, Grant MK, Pitstick R, Carlson GA, Lanier LM, Yuan LL, Ashe KH, Liao D: Tau mislocalization to dendritic spines mediates synaptic dysfunction independently of neurodegeneration. Neuron 2010, 68:1067-1081.

64. Cook C, Gendron TF, Scheffel K, Carlomagno Y, Dunmore J, DeTure M, Petrucelli L: Loss of HDAC6, a novel CHIP substrate, alleviates abnormal tau accumulation. Hum Mol Genet 2012, 21:2936-2945.

65. Tsai NP, Tsui YC, Wei LN: Dynein motor contributes to stress granule dynamics in primary neurons. Neuroscience 2009, 159:647-656.

66. Wu CH, Fallini C, Ticozzi N, Keagle PJ, Sapp PC, Piotrowska K, Lowe P, Koppers M, McKenna-Yasek D, Baron DM, Kost JE, Gonzalez-Perez P, Fox AD, Adams J, Taroni F, Tiloca C, Leclerc AL, Chafe SC, Mangroo D, Moore MJ, Zitzewitz JA, Xu ZS, van den Berg LH, Glass JD, Siciliano G, Cirulli ET, Goldstein DB, Salachas F, Meininger V, Rossoll W, Ratti A, Gellera C, Bosco DA, Bassell GJ, Silani V, Drory VE, Brown RH, Landers JE: Mutations in the profilin 1 gene cause familial amyotrophic lateral sclerosis. Nature 2012, 488:449-503.

67. Munch C, Sedlmeier R, Meyer T, Homberg V, Sperfeld AD, Kurt A, Prudlo J, Peraus G, Hanemann CO, Stumm G, Ludolph AC: Point mutations of the p150 subunit of dynactin (DCTN1) gene in ALS. Neurology 2004, 63:724-726.

68. Vilarino-Guell C, Wider C, Soto-Ortolaza Al, Cobb SA, Kachergus JM, Keeling BH, Dachsel JC, Hulihan MM, Dickson DW, Wszolek ZK, Uitti RJ, Graff-Radford NR, Boeve BF, Josephs KA, Miller B, Boylan KB, Gwinn K, Adler CH, Aasly JO, Hentati F, Destee A, Krygowska-Wajs A, Chartier-Harlin MC, Ross OA, Rademakers R, Farrer MJ: Characterization of DCTN1 genetic variability in neurodegeneration. Neurology 2009, 72:2024-2028.

69. Tsai NP, Wei LN: RhoA/ROCK1 signaling regulates stress granule formation and apoptosis. Cell Signal 2010, 22:668-675.

70. Hua $Y$, Zhou J: Survival motor neuron protein facilitates assembly of stress granules. FEBS Lett 2004, 572:69-74.

71. Furukawa Y, Kaneko K, Matsumoto G, Kurosawa M, Nukina N: Cross-seeding fibrillation of $\mathrm{Q} / \mathrm{N}$-rich proteins offers new pathomechanism of polyglutamine diseases. J Neurosci 2009, 29:5153-5162.

72. Gehrke S, Imai Y, Sokol N, Lu B: Pathogenic LRRK2 negatively regulates microRNA-mediated translational repression. Nature 2010, 466:637-641.

73. Waxman EA, Giasson BI: Induction of intracellular tau aggregation is promoted by alpha-synuclein seeds and provides novel insights into the hyperphosphorylation of tau. J Neurosci 2011, 31:7604-7618.

74. Kampers T, Friedhoff P, Biernat J, Mandelkow EM, Mandelkow E: RNA stimulates aggregation of microtubule-associated protein tau into Alzheimer-like paired helical filaments. FEBS Lett 1996, 399:344-349.

75. Butterfield DA, Dalle-Donne I: Redox proteomics. Antioxid Redox Signal 2012, 17:1487-1489 
76. Craft S: The role of metabolic disorders in Alzheimer disease and vascular dementia: two roads converged. Arch Neurol 2009, 66:300-305.

77. Goldstein LE, Fisher AM, Tagge CA, Zhang XL, Velisek L, Sullivan JA, Upreti C, Kracht JM, Ericsson M, Wojnarowicz MW, Goletiani CJ, Maglakelidze GM, Casey N, Moncaster JA, Minaeva O, Moir RD, Nowinski CJ, Stern RA, Cantu RC, Geiling J, Blusztajn JK, Wolozin BL, Ikezu T, Stein TD, Budson AE, Kowall NW, Chargin D, Sharon A, Saman S, Hall GF, Moss WC, Cleveland RO, Tanzi RE, Stanton PK, McKee AC: Chronic traumatic encephalopathy in blastexposed military veterans and a blast neurotrauma mouse model. Sci Trans/ Med 2012, 4:134ra60.

78. Lagier-Tourenne C, Polymenidou M, Hutt KR, Vu AQ, Baughn M, Huelga SC, Clutario KM, Ling SC, Liang TY, Mazur C, Wancewicz E, Kim AS, Watt A, Freier S, Hicks GG, Donohue JP, Shiue L, Bennett CF, Ravits J, Cleveland DW, Yeo GW: Divergent roles of ALS-linked proteins FUS/TLS and TDP-43 intersect in processing long pre-mRNAs. Nat Neurosci 2012, 15:1488-1497.

79. Klebe S, Lossos A, Azzedine H, Mundwiller E, Sheffer R, Gaussen M, Marelli C, Nawara M, Carpentier W, Meyer V, Rastetter A, Martin E, Bouteiller D, Orlando L, Gyapay G, El-Hachimi KH, Zimmerman B, Gamliel M, Misk A, Lerer I, Brice A, Durr A, Stevanin G: KIF1A missense mutations in SPG30, an autosomal recessive spastic paraplegia: distinct phenotypes according to the nature of the mutations. Eur J Hum Genet 2012, 20:645-649.

80. Harms MB, Ori-McKenney KM, Scoto M, Tuck EP, Bell S, Ma D, Masi S, Allred P, Al-Lozi M, Reilly MM, Miller LJ, Jani-Acsadi A, Pestronk A, Shy ME, Muntoni F, Vallee RB, Baloh RH: Mutations in the tail domain of DYNC1H1 cause dominant spinal muscular atrophy. Neurology 2012, 78:1714-1720.

81. Hafezparast M, Klocke R, Ruhrberg C, Marquardt A, Ahmad-Annuar A, Bowen S, Lalli G, Witherden AS, Hummerich H, Nicholson S, Morgan PJ, Oozageer R, Priestley JV, Averill S, King VR, Ball S, Peters J, Toda T, Yamamoto A, Hiraoka Y, Augustin M, Korthaus D, Wattler S, Wabnitz P, Dickneite C, Lampel S, Boehme F, Peraus G, Popp A, Rudelius M, Schlegel J, Fuchs H, Hrabe de Angelis M, Schiavo G, Shima DT, Russ AP, Stumm G, Martin JE, Fisher EM: Mutations in dynein link motor neuron degeneration to defects in retrograde transport. Science 2003, 300:808-812.

82. Youle RJ, van der Bliek AM: Mitochondrial fission, fusion, and stress. Science 2012, 337:1062-1065.

83. Quadri M, Cossu G, Saddi V, Simons EJ, Murgia D, Melis M, Ticca A, Oostra BA, Bonifati V: Broadening the phenotype of TARDBP mutations: the TARDBP Ala382Thr mutation and Parkinson's disease in Sardinia. Neurogenetics 2011, 12:203-209.

84. Higashi S, Moore DJ, Colebrooke RE, Biskup S, Dawson VL, Arai H, Dawson TM, Emson PC: Expression and localization of Parkinson's disease-associated leucine-rich repeat kinase 2 in the mouse brain. J Neurochem 2007, 100:368-381.

85. Nakashima-Yasuda H, Uryu K, Robinson J, Xie SX, Hurtig H, Duda JE, Arnold SE, Siderowf A, Grossman M, Leverenz JB, Woltjer R, Lopez OL, Hamilton R, Tsuang DW, Galasko D, Masliah E, Kaye J, Clark CM, Montine TJ, Lee VM, Trojanowski JQ: Co-morbidity of TDP-43 proteinopathy in Lewy body related diseases. Acta Neuropathol 2007, 114:221-229.

86. Arai T, Mackenzie IR, Hasegawa M, Nonoka T, Niizato K, Tsuchiya K, Iritani S, Onaya M, Akiyama H: Phosphorylated TDP-43 in Alzheimer's disease and dementia with Lewy bodies. Acta Neuropathol 2009, 117:125-136.

87. Rhinn H, Qiang L, Yamashita T, Rhee D, Zolin A, Vanti W, Abeliovich A: Alternative alpha-synuclein transcript usage as a convergent mechanism in Parkinson's disease pathology. Nat Commun 2012, 3:1084.

doi:10.1186/1750-1326-7-56

Cite this article as: Wolozin: Regulated protein aggregation: stress granules and neurodegeneration. Molecular Neurodegeneration 2012 7:56.

\section{Submit your next manuscript to BioMed Central and take full advantage of:}

- Convenient online submission

- Thorough peer review

- No space constraints or color figure charges

- Immediate publication on acceptance

- Inclusion in PubMed, CAS, Scopus and Google Scholar

- Research which is freely available for redistribution

Submit your manuscript at www.biomedcentral.com/submit
() Biomed Central 